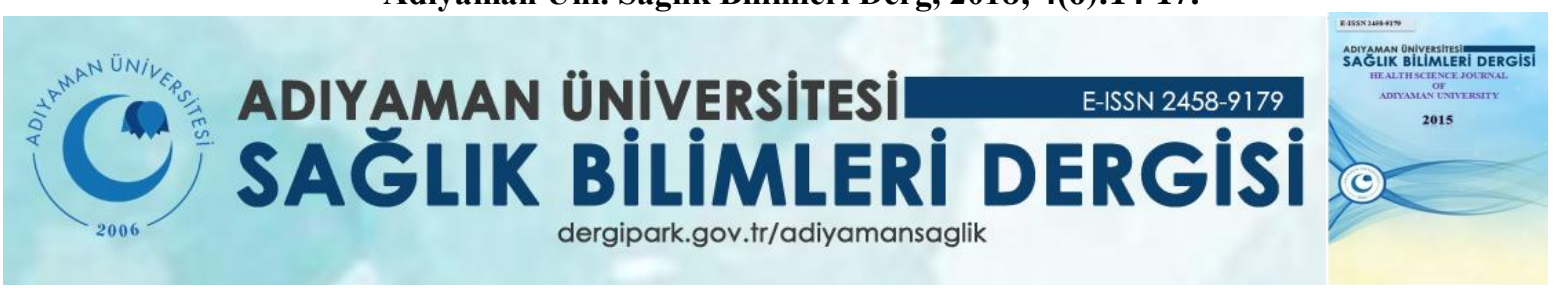

\title{
Olgu Sunumu/Case Report \\ Olgu Sunumu: İki Yıl Sonra Diğer Overde Tekrar Eden Müsinoz Kistadekarsinom
}

\author{
Pervin Karl1 ${ }^{1}$, Osman Fadıl Kara ${ }^{1}$ \\ ${ }^{1}$ Amasya Üniversitesi Tıp Fakültesi Kadın Hastalıkları ve Doğum AD
}

\begin{abstract}
Özet:
Over kanserleri jinekolojik maligniteler içerisinde sıklıkla görülen malignitelerdendir. Semptomatik olarak prezentasyonu orjini ile bağlantılı olmak üzere, büyüklük ve yaş ile de bağlantılıdır. Tanı için en değerli yöntemlerden biri ultrasonografidir. Bilgisayarlı tomografi (BT) ve magnetik rezonans görüntüleme(MRI) yöntemleri de ayrıcı tanıda kullanılmalıdır. Olgu: 35 yaşında bir hastaya 2 yı önce başka bir merkezde müsinöz kistadenokarsinoma nedeniyle cerrahi yapılmıştı. Hasta bize karında şişlik ve ağrı ile geldi. Ultrasonografi ve tetkiklerinin yapılmasından sonra cerrahi planlandı. Cerrahi sırasında; kitle spontan rüptüre olmuş ve yer yer nekrotik alan içeriyordu. Biz bu dev over malignitesini ve müsinöz materyali ile peritonite sebep olan olguyu paylaşmayı amaçladık.
\end{abstract}

Anahtar Kelimeler: müsinöz kistadenokarsinom, şişkinlik, pelvik peritonit, fertilite koruyucu cerrahi

\section{A Case Report: Recurring Mucinous Cystadenocarcinoma On Other Ovary Two Years Later}

\section{Abstract:}

Ovarian cancers are frequently seen among gynecological malignancies. Symptomatically, the presentation is also related to size and age, in connection with the origina. Ultrasonography is one of the most valuable method for diagnosis. Computed tomography and magnetic resonance imaging methods should also be used in differential diagnosis. Case: 35-year old patient had undergone surgery due to müsinous cystadenocarcinoma in other center 2 years ago. The patient came to us with abdominal swelling and pain. Surgery was planned after Ultrasonogaphy and examinations. During the surgical procedure, the mass was spontaneously become rupture and involved necrotic field. We wanted to share the situation that caused this giant over-malignancy and mucinous material

Keywords: Mucinous cystadenocarcinoma, bloating, pelvic peritonitis, fertility protective surgery

\begin{tabular}{l}
\hline Yazışmadan Sorumlu Yazar \\
\hline Pervin Karlı \\
Amasya Üniversitesi Tıp Fakültesi Kadın Hastalıkları ve \\
Doğum AD \\
Tel : +90 35821840 00-18 05 \\
Email: parpi2300@hotmail.com \\
\hline
\end{tabular}

DOI:10.30569/adiyamansaglik .439484

\begin{tabular}{ll}
\hline Geliş Tarihi: & $\mathbf{0 1 . 0 7 . 2 0 1 8}$ \\
\hline Kabul Tarihi: & $\mathbf{1 2 . 0 7 . 2 0 1 8}$ \\
\hline
\end{tabular}




\section{Giriş:}

Over kanserleri mortalite oranı en yüksek ve en s1k görülen ikinci jinekolojik kanserdir $(1,2)$.

Klinik olarak semptom verdiğinde genellikle ileri evre olup evre 3-4'dür. Genellikle \%15-20 oranında bilateral görülür ve çok büyük boyutlara ulaşır. CA-125 düzeyi hastaların yarısında yüksek bulunabilir. Ultrasonografi duyarlı fakat nonspesifik bir metottur. BT ve MRI tanıda yardımcı olabilir $(3,4,5)$. Doppler kullanımı tanıda daha fazla fikir vermez $(6,7)$.

Olgu: 35 yaşında hasta bize karında şişlik ile başvurdu. Hastanın başvurduğunda şişlik dışında batında hassasiyet ve ateş semptomları mevcuttu. Pelvik kitle ve eşlik eden pelvik peritonit düşünülerek hastaya 3 gün antibiyoterapi uygulandı ve hastanın kliniği düzeldikten sonra ilave görüntüleme yöntemleri (BT, MRI) çekildi ve ultrasonografiye üstünlük sağlayacak bir ön tanıya ulaşılamadı. Pelvik kitle ve apse şüphesi ile hasta laparotomiye alındı. Hastanın batınını umblikusun üzerine ksifoid kemiğe kadar ulaşan kitle ve batında yaygın müsinöz materyal görüldü. Kitlenin over dokusu ile birlikte eksizyonu yapıldı (Şekil 1). Frozen ile müsinöz kistadenokarsinom tanısı konuldu.

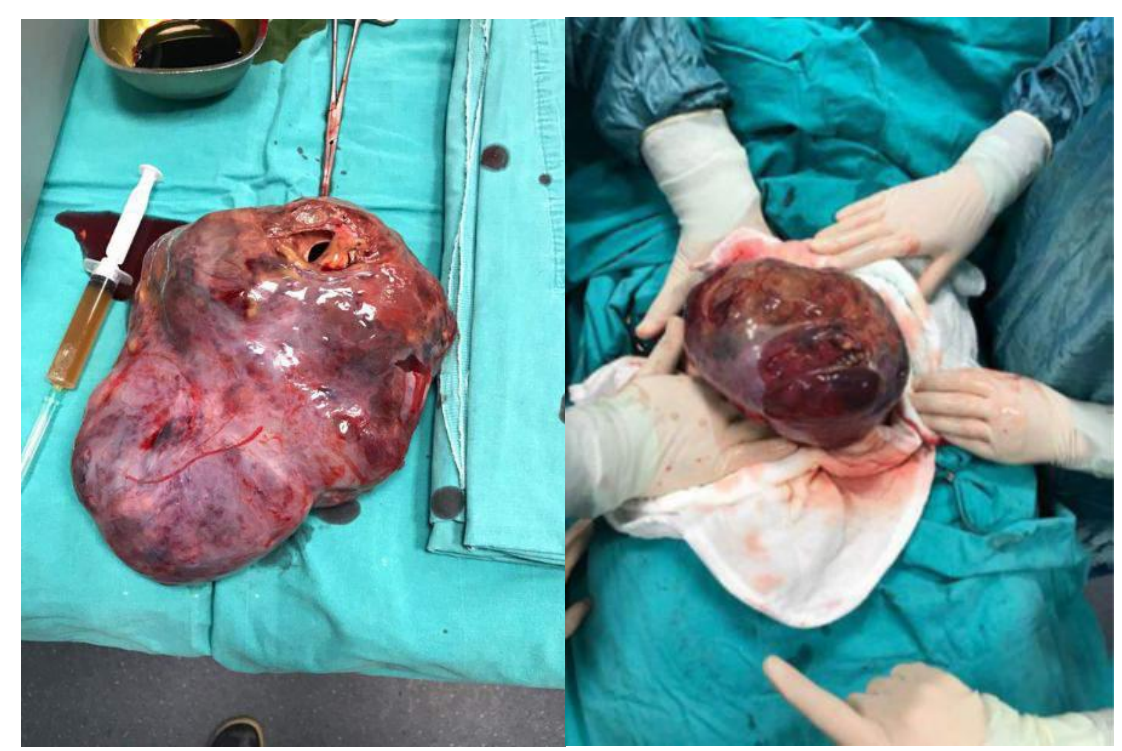

Resim 1: Olgunun operasyon sırasında ve sonrasındaki görünümü 


\section{Tartışma:}

Over kanserleri jinekolojik kanserler arasında ikinci en sık görülen kanser olup oldukça mortal seyreder ve ileri evrede karşımıza çıkar. Müsinöz tipleri çok büyük boyutlara ulaşır ve bazen psödomiksoma peritonei (PMP) gibi bir klinik tablo ile karşımıza çıkabilir. Olgu başka bir merkezde 2 yıl önce geçirmiş olduğu operasyonda diğer overde aynı teşhis ile ooferektomi geçirmiş ve fertilite arzusu nedeniyle tek overi bırakılmıştı. Bu durum bize over kanseri cerrahisi planlarken fertilite korumak amaçlı bıraktığımız sağlam görünümlü diğer overden de biyopsi yapmanın önemini, diğer overi bırakırken \% 15-20 oranında bilateral görülebileceğini ve müsinöz kistik içeriğin peritonit tablosu ile karşımıza çıkabileceğini göstermektedir. Bu hastalara fertilite koruyucu yaklaşımda bulunurken ve organ koruyucu yaklaşım planlarken mutlaka iyi karar verilmeli, hasta bilgilendirilmeli, aydınlatılmış onam alınmalı ve oosit dondurma gibi fertiliteye yönelik diğer yöntemler hastaya sunulmalıdır. Karar verirken tüm bu konuların hasta ile paylaşılması sonucunda cerrahi tedavinin dikkatle planlanması gerekmektedir. Bizim olgumuzda PMP gelişmiş ve ona sekonder peritonit şeklinde akut bir olgu olarak başvurmuştu. PMP benign veya malign over ve appendiks tümörlerinde görülebilen bir durumdur. Bu durum peritonda müsinöz implantlardan oluşur ve oldukça nadirdir (8). Bu olguda da literatürde bahsedildiği gibi müsinöz kistadenokarsinom çok büyük boyutlara ulaşmış ve kendini psödomiksoma peritonei olarak göstermiştir. 


\section{Kaynaklar:}

1. Sassone AM, Timor-Tritsch IE, Artner A, Westhoff, C, Warren WB. Transvaginal sonographic characterization of ovarian disease: evaluation of a new scoring system to predict ovarian malignancy. Obstetrics and gynecology, 1991;78(1), 70-76.

2. Andolf E, Joergensen C. A prospective comparison of clinical ultrasound and operative examination of the female pelvis. Journal of ultrasound in medicine, 19887(11), 617-620.

3. Rieber A, Nüssle K, Stöhr I, Grab D, Fenchel S, Kreienberg R, Brambs HJ. Preoperative diagnosis of ovarian tumors with MR imaging: comparison with transvaginal sonography, positron emission tomography, and histologic findings. American Journal of Roentgenology, 20011;77(1), 123-129.

4. Taner CE, Başoğul Ö, Semih MUN, MIZRA T, DERIN G. Overin Müsinöz Kistadenokarsinomları ve Sassone Skorlama Sistemi. Kocatepe Tip Dergisi, 2005;6(2).

5. Zarcone, R, Bellini P, Carfora E, Monarca M, Longo M, Cardone A. Role of ultrasonography in the early diagnosis of ovarian cancer. European journal of gynaecological oncology, 1997;18(5), 418-419.

6. Teneriello MG, Park RC. Early detection of ovarian cancer. CA: a cancer journal for clinicians, 1995;45(2), 71-87.

7. Goff BA, Mandel L, Muntz HG, Melancon CH. Ovarian carcinoma diagnosis: results of a national ovarian cancer survey. Cancer: Interdisciplinary International Journal of the American Cancer Society, 20008;9(10),2068-2075.

8. Yeh H, Shafir MK, Slater G, Meyer RJ, Cohen BA, Geller SA. Ultrasonography and computed tomography in pseudomyxoma peritonei. Radiology. 1984;153(2), 507-510. 